\title{
Desambiguação dos Termos Mapeamento Topográfico em Grandes Escalas e Mapeamento Cadastral no Brasil
}

\author{
Disambiguation of the Terms of Large Scale Topographic Mapping and \\ Cadastral Mapping in Brazil
}

Adriana Alexandria Machado ${ }^{1}$
Silvana Philippi Camboim $^{2}$

Recebido em setembro de 2018. Aprovado em maio de 2019.

\begin{abstract}
RESUMO
Os municípios são prestadores de serviços diretos à população, por excelência. No Brasil, a competência para produção do mapeamento topográfico em grandes escalas (maiores do que 1:25.000), necessário ao planejamento urbano e ao Cadastro Territorial Multifinalitário nas cidades, é compartilhada entre a União, estados e municípios. Com base em iniciativas de integração de dados geoespaciais como a INDE e o SINTER, há uma crescente necessidade de normas e padrões que permitam a interoperabilidade entre as bases produzidas por atores diversos. No entanto, entre produtores e usuários de dados cartográficos urbanos, não há consenso em relação ao uso dos termos mapeamento topográfico em grandes escalas e mapeamento cadastral. No Brasil, esses termos são historicamente utilizados como sinônimos, colaborando para que iniciativas e esforços para normatizá-los e atualizá-los não tenham sido profícuos. O objetivo deste artigo, através de revisão da literatura, é comparar as definições de mapeamento topográfico em grandes escalas e mapeamento cadastral com o intuito de clarificar o entendimento e o uso destes dois termos no país. São examinadas as definições clássicas e as adotadas pelas agências nacionais de mapeamento, além daquelas encontradas na legislação, especificações e normas nacionais. Adicionalmente é feita uma discussão sobre a mesclagem dos termos no país. Como resultados, são apresentadas sugestões de definições para cada um dos termos. Com a desambiguação dos termos, espera-se contribuir para a estruturação e consolidação das normas para um mapeamento topográfico em grandes escalas e para um mapeamento cadastral padronizados e atualizados com a participação dos diversos atores envolvidos.
\end{abstract}

\footnotetext{
1 Programa de Pós-graduação em Ciências Geodésicas da Universidade Federal do Paraná (UFPR), Brasil. E-mail: adri.alexandria@gmail.com

2 Programa de Pós-graduação em Ciências Geodésicas da Universidade Federal do Paraná (UFPR), Brasil. E-mail: silvanacamboim@gmail.com
} 
PALAVRAS-CHAVE: Mapeamento Topográfico em Grandes Escalas. Mapeamento Cadastral. Interoperabilidade de Dados Geoespaciais. Semântica de Dados Geoespaciais.

\begin{abstract}
The local government is the main provider of direct services to the population. In Brazil, the competence to produce topographic mapping at large scales (greater than 1: 25,000), required for urban planning and the Cadastre in cities, is shared between the Union, the states and the municipalities. Based on geospatial data integration initiatives, such as INDE and SINTER, there is a growing need for standards that allow interoperability between the bases produced by diverse actors. However, among the producers and users of urban cartographic data, there is no consensus regarding the use of the terms topographic mapping in large scales and cadastral mapping. In Brazil, these two terms are historically used as synonyms, collaborating so that initiatives and efforts to standardize and update them have not been fruitful. The objective of this article is to search the literature and compare the definitions of topographic mapping in large scales and cadastral mapping in order to clarify the understanding and the use of these two terms in the country. The method used is the literature review. The classic definitions and those adopted by the national mapping agencies are examined in addition to those found in national legislation, specifications and standards. In addition, a discussion on the merge of the terms in the country is made. As a result, definitions suggestions are presented for each of the terms. With the disambiguation of these two terms, it is hoped to contribute to the structuring and consolidation of standards for a large-scale topographic mapping and a cadastral mapping, standardized and updated, in Brazil, in accordance with the guidelines of the National Spatial Data Infrastructure (INDE), and with the participation of the actors involved, be they from the public sector, private sector or society in general.
\end{abstract}

KEYWORDS: Large-Scale Topographic Mapping. Cadastral Mapping. Geospatial Data Interoperability. Geospatial Data Semantics.

\title{
Introdução
}

O mapeamento topográfico provê a base fundamental para o conhecimento do território e tem papel relevante em aplicações geoespaciais e iniciativas como a INDE (Infraestrutura Nacional de Dados Espaciais) (BRASIL, 2010a; CAMBOIM et al., 2009).

O mapeamento sistemático terrestre, executado no Brasil pelo Instituto Brasileiro de Geografia e Estatística (IBGE) e pela Diretoria do Serviço Geográfico (DSG) do Exército Brasileiro, cobre o território de forma 
desigual entre as pequenas e médias escalas (1:25.000 e menores), além de muitas vezes estar desatualizado (CAMBOIM, BRAVO e SLUTER, 2015; CARISSIMI, ETGES e COLLISHONN, 2011; PEREIRA, et al., 2003). Em relação ao mapeamento topográfico em grandes escalas (maiores do que 1:25.000), necessário ao planejamento urbano e ao Cadastro Territorial Multifinalitário nas cidades, a situação é ainda mais complicada. A competência para sua produção é compartilhada entre a União, os estados e os municípios, envolvendo atores e realidades diversas, além de uma lacuna de legislação e normas específicas que atendam às peculiaridades deste tipo de mapeamento no país (BRASIL, 1967; BRASIL, 2010a; BRASIL, 2010b). Somente em 2016 foram lançadas a Especificação Técnica para a Estruturação dos Dados Geoespaciais Vetoriais de Defesa da Força Terrestre (ET-EDGV Defesa F Ter) (DSG, 2016a) e a Especificação Técnica para a Aquisição dos Dados Geoespaciais Vetoriais de Defesa da Força Terrestre (ET-ADGV Defesa F Ter) (DSG, 2016b), englobando as grandes escalas e constituindo-se em importantes normas para a produção dos novos mapeamentos.

Em um estudo sobre a utilização e compartilhamento de dados geoespaciais entre os profissionais que trabalham nas instituições públicas e prefeituras da Região Metropolitana de Curitiba (RMC), estes relataram que entre os dados mais utilizados estão o mapeamento topográfico em grandes escalas, os nomes geográficos e a divisão político-administrativa, o que demonstra a necessidade de dados com maior nível de detalhamento. Contudo, o estudo revela que existe a necessidade de ajuste nos dados compartilhados, principalmente no que diz respeito à padronização dos dados, atualização, dificuldade em lidar com a mudança de sistema geodésico de referência, além da falta de metadados, o que evidencia a falta de legislação que designe as normas e padrões para a produção cartográfica nas grandes escalas (MACHADO e CAMBOIM, 2016).

Os usuários de mapas em grandes escalas, descritos no documento da CONCAR (2006), no contexto da utilização das bases cartográficas 
municipais no Censo do ano 2000 pelo IBGE, relataram dificuldades semelhantes: geometria com problemas, formatos de arquivos diferentes, divergências toponímicas, diversas escalas, limites, sistemas de projeção, referenciais geodésicos e falta de metadados. Em decorrência destes problemas, em novembro de 2006 foi criado o Comitê de Normatização do Mapeamento Cadastral Municipal (CNMC) pela CONCAR com o objetivo de:

Propor normas para mapeamento cadastral, até hoje inexistente, suprindo as municipalidades e demais órgãos governamentais que se incumbem da produção/contratação de serviços, uso e gestão de informações relacionadas com infra-estrutura urbana e municipal (CONCAR, 2006).

Foram realizadas reuniões de 2007 a 2012, mas não foram divulgados resultados até o momento.

Por ocasião do lançamento da proposta de atualização do sistema de referência, através do Projeto Mudança do Referencial Geodésico (PMRG) do IBGE no ano 2000, foi criado um grupo de trabalho denominado GT6 Grupo de Normatização e Legislação. O objetivo do grupo foi elaborar uma proposta para atualização da legislação cartográfica, principalmente no que se refere às diretrizes e bases da cartografia brasileira. Entre as sugestões do GT6 estavam a inclusão da cartografia cadastral no decreto $\mathrm{n}^{\circ} 243$ (BRASIL, 1967) entre outras questões (PEREIRA, et al., 2003).

Tanto nos documentos do Comitê de Normatização do Mapeamento Cadastral Municipal (CNMC) quanto do GT6, pode-se observar a utilização do termo mapeamento/cartografia cadastral com referência ao mapeamento topográfico em grandes escalas. Mais recentemente, uma série de iniciativas está procurando estruturar e padronizar o Cadastro Territorial Multifinalitário (BRASIL, 2016; BRASIL, 2010b). Dentre elas está o Manual de Apoio - Diretrizes para a Criação, Instituição e Atualização do Cadastro Territorial Multifinalitário nos Municípios Brasileiros do Ministério das Cidades, que ressalta que não é produzido um mapeamento sistemático em grandes escalas no país, bem como normas para representação cartográfica 
oficial nacional que as contemplem (BRASIL, 2010b, p. 37-38). E acrescenta que:

No Brasil, não há uma normatização nacional que defina a representação cartográfica dos elementos gráficos de interesse à cartografia cadastral. Entretanto, é fundamental que se apresentem nessa cartografia, de modo claro e hierarquizado, os elementos definidores da rigidez geométrica, nos seus diferentes níveis de levantamento (BRASIL, 2010b, p. 40).

Recentemente, o decreto número 8.764/2016 (BRASIL, 2016) instituiu a criação do Sistema Nacional de Gestão de Informações Territoriais (SINTER), uma ferramenta de gestão pública que pretende agregar informações registrais, cadastrais, fiscais e geoespaciais oriundas da administração pública da União, dos estados, do Distrito Federal, dos municípios e de pessoas jurídicas de direito privado. O sistema será administrado pela Secretaria da Receita Federal e receberá as informações relacionadas à titularidade dos bens imobiliários por meio dos sistemas de registros eletrônicos dos cartórios de registro de imóveis (IRIB, 2016; BRASIL, 2016).

Contudo, para produzir um sistema nacional padronizado nestes moldes é importante haver como base um mapeamento topográfico em grandes escalas que também seja padronizado.

É consenso que a falta de normas e padrões para os mapeamentos em grandes escalas, sejam elas de referência ou cadastrais são empecilhos ao estabelecimento de uma cartografia efetiva no país (HASENACK, CABRAL e PHILIPS, 2013; CARISSIMI, et al., 2011; BRASIL, 2010b; CONCAR, 2006; PEREIRA, et al., 2003). Entretanto, não existe consenso em relação ao uso dos termos mapeamento topográfico em grandes escalas e mapeamento cadastral na comunidade de geoinformação no país. No Brasil, estes dois termos são historicamente utilizados como sinônimos, colaborando para dificultar o diálogo da comunidade técnico-científica da área e criando obstáculos para os esforços de normatização. 
Antes de iniciar a comparação das definições para desambiguação dos termos, torna-se necessário entender o sentido da palavra "limites" nos conceitos de cada um dos mapeamentos analisados.

Para as definições de mapeamento topográfico em grandes escalas foi adotado o significado do termo definido na ontologia de domínio de (CASTAÑEDA FILHO, 2017, pg. 71, vol. 1) o qual diz que, "limite" é uma "linha que delimita completamente um território", seja ele nacional, estadual ou municipal. Castañeda Filho (2017, pg. 236, vol.1), concluiu que existe a relação de dependência entre uma divisão territorial e o seu limite:

\begin{abstract}
No domínio das divisões e limites territoriais brasileiros, as instâncias de território terrestre de entes geopolíticos e político-administrativos - o Estado federal brasileiro, as unidades federativas e os municípios - são chamadas divisões territoriais (terrestres), a cada uma das quais corresponde uma instância de limite fiat institucional, aqui denominado limite territorial (ou limite terrestre), segundo a concepção unária de limite.
\end{abstract}

A concepção do autor (CASTAÑEDA FILHO, 2017) está em sintonia com a descrição semântica da ET-EDGV 3.0 - Especificações Técnicas para Estruturação de Dados Geoespaciais Vetoriais (DSG, 2017) para área político-administrativa que compreende o país, os entes federados, os territórios federais e distritos. É possível perceber também, que há uma delimitação hierárquica que não entra na espacialização da cartografia cadastral. Isso ocorre porque os limites, sejam eles do território nacional ou dentro dos municípios, são criados por legislação específica na sua hierarquia de origem.

Sendo assim, ao longo do artigo foi utilizado o termo "limite territorial" quando se trata de mapeamento topográfico em grandes escalas.

Para as definições de mapeamento cadastral foi adotado o significado do termo dado pelo artigo 15 da portarian ${ }^{\circ} 511$ de 2009 do Ministério das Cidades (BRASIL, 2009). O significado do termo "limite" no mapeamento cadastral não difere conceitualmente do significado no mapeamento topográfico em grandes escalas, já que o mapeamento cadastral deve 
obedecer às normas da cartografia nacional. Entretanto, no contexto do Cadastro, a definição de limites tem uma ordem de precedência, dado que o objeto de demarcação é o limite das parcelas:

Art. 15 Os limites territoriais são cadastrados com atributos específicos, conforme a seguinte ordem de preferência: I - das parcelas; II - das áreas de posse, correspondentes ao limite físico; III - das propriedades, correspondentes ao limite legal; IV - dos setores cadastrais ou de zoneamento; V - dos distritos; VI - dos Municípios; VII - dos Estados; VIII - do País (BRASIL, 2009).

Desse modo, a portaria (BRASIL, 2009) considera os casos nos quais alguns desses limites podem coincidir. Por exemplo, no caso de um imóvel localizado entre dois municípios, o imóvel será dividido em duas parcelas, cada uma com um identificador inequívoco e pertencente a cada um dos municípios.

Então, ao longo do artigo quando se trata de mapeamento cadastral, foi utilizado o termo "limite das parcelas".

\section{Conceito de Mapeamento Topográfico em Grandes Escalas}

O mapeamento topográfico de referência é produto de um conjunto de procedimentos cujo objetivo é a representação do espaço territorial através de séries de mapas em escalas padrão. A importância do mapeamento topográfico reside no grande número de aplicações nas quais pode ser utilizado como: posicionamento e orientação no espaço geográfico, suporte a outros tipos de mapeamento (incluindo o cadastral), suporte ao planejamento em diversos níveis, base para anteprojetos de engenharia, base para projetos ambientais, entre outros (IBGE, 2018).

O primeiro mapeamento topográfico de referência semelhante aos mapeamentos atuais, utilizando métodos geodésicos, foi realizado na França por César-François Cassini de Thury e seus engenheiros a pedido do rei Luís XV no ano de 1747. As medições foram efetuadas em duas campanhas entre os anos de 1750 e 1789. O mapeamento de todo o país, dividido em várias 
cartas na escala 1:86.000 - uma escala grande, dado que anteriormente os mapas representavam todo o país em uma folha apenas - foi lançado em 1815 (PERRET, GRIBAUDI e BARTHELEMY, 2015; KONVITZ, 1990)

O termo "grandes escalas" refere-se à representação de feições com alto nível de detalhamento e são expressas por diferentes proporções dependendo do país ou das necessidades de uso, mas a literatura mostra que elas variam entre 1:10.000 e 1:500 (OLTEANU-RAIMOND, et al., 2017; REGISTERS OF SCOTLAND, 2017b; BRASIL, 2010b). No Brasil, a Especificação Técnica para Aquisição de Dados Geoespaciais Vetoriais de Defesa da Força Terrestre (ET-ADGV) (DSG, 2016b) considera as escalas 1:10.000 e 1:1.000 como mapeamento de referência, mas admite as escalas intermediárias entre elas e recomenda que, sejam adotados os mesmos critérios de medidas da escala 1:1.000 para aquelas maiores que 1:5.000, e os mesmos critérios de medidas da escala 1:10.000 para as escalas menores ou iguais a 1:5.000.

É importante destacar que, apesar se ser dividido em séries de pequenas e grandes escalas nos mapeamentos de referência oficiais, o conceito de mapeamento topográfico independe da sua escala de representação. De acordo com KEATES (1973) nos mapas topográficos são representadas "todas as feições identificáveis da superfície da Terra, tanto naturais como artificiais, para as quais é possível estabelecer uma posição específica, expressa em relação à superfície topográfica” e, seu propósito fundamental é representar as feições em suas posições, acurada e precisamente, dentro dos limites da escala.

Para DENT (1999), “mapas topográficos são mapas de uso geral, cuja ênfase está na localização". Eles representam os objetos naturais e os construídos pela humanidade como: hidrografia, vegetação, relevo, estradas, edificações, limites territoriais, entre outros.

De acordo com a agência de mapeamento do Canadá (NATURAL RESOURCES CANADA, 2017, pg. 1) um mapa topográfico: 
É uma ilustração detalhada e acurada de feições naturais e feitas pelo homem no terreno como estradas, ferrovias, linhas de transmissão de energia, curvas de nível, elevações, rios, lagos e nomes geográficos.

Estas feições são divididas nas categorias relevo, hidrografia, vegetação, transporte, cultura e limites territoriais.

Para o United States Geological Survey (USGS) dos Estados Unidos (USGS, 2008):

Seja em papel ou na tela de um computador, um mapa é a melhor ferramenta disponível para catalogar e visualizar a disposição das coisas na superfície da terra. (...) A característica que distingue um mapa topográfico de outros tipos de mapas é o uso de curvas de nível para representar a forma e elevação da superfície da Terra. Os mapas topográficos representam as elevações e depressões tridimensionais do terreno sobre uma superfície bidimensional.

A agência de mapeamento da Nova Zelândia (LAND INFORMATION NEW ZEALAND, 2017) define os mapas topográficos como "representações gráficas dos elementos que aparecem na superfície da Terra, as quais incluem feições culturais, de hidrografia, relevo e vegetação”.

Entre as definições expostas percebe-se que existe consenso de que os mapas topográficos são mapas de uso geral que mostram a localização acurada e precisa de uma variedade de feições. As duas próximas definições nos levam um pouco além na compreensão deste conceito, quando falam do seu uso.

A agência de mapeamento do governo australiano (GEOSCIENCE AUSTRALIA, 2017) diz que mapas topográficos são representações gráficas detalhadas e acuradas de feições que aparecem na superfície da Terra. Estas feições incluem elementos culturais como vias e edificações, nomes de lugares, limites territoriais e áreas de proteção; elementos da hidrografia como lagos e rios; elementos do relevo como montanhas; elementos da vegetação como áreas de floresta e desmatadas. Quanto à utilidade, a Geoscience Australia diz que os mapas topográficos são utilizados para (grifo nosso) fins recreativos como viagens, caminhadas e orientação, mas também 
são utilizados pelo governo e pela indústria para auxiliar no planejamento urbano, na mineração, na gestão de emergências e para o estabelecimento de limites legais e de propriedade da terra (GEOSCIENCE AUSTRALIA, 2017).

O Ordnance Survey (OS) (ORDNANCE SURVEY, 2017, pg. 12), agência de mapeamento da Grã-Bretanha, afirma que o OS MasterMap Topography Layer, o mapa topográfico do país em formato de banco de dados geoespaciais, contém:

Feições que representam objetos do ambiente físico como edificações, campos, cercas e listagem de endereços. Ele também inclui objetos intangíveis como limites municipais e as linhas de águas médias, altas ou baixas.

O OS descreve a utilidade do mapa topográfico (grifo nosso), como base para as mais diversas e elaboradas aplicações como: gestão do território e projetos imobiliários, localização de obras de energia, comunicações e saneamento, registro de imóveis para autoridades locais, monitoramento ambiental, estudos de implantação, serviços ao cidadão, turismo, avaliação de riscos, serviços baseados em localização em dispositivos móveis e centros de atendimento a usuários, entre outros (ORDNANCE SURVEY, 2017).

Ao descrever que os mapas topográficos servem como base a tão diversificadas finalidades, reafirma-se que os mapas topográficos são mapas de uso geral que devem servir a todos os tipos de usos e usuários. Os usos destacados acima têm como base os mapas topográficos em grandes escalas, sobre os quais são adicionadas outras informações em âmbito municipal, as quais fazem parte do chamado mapeamento cadastral, cujo conceito é tratado na próxima seção.

\section{Conceito de Mapeamento Cadastral}


O mapeamento cadastral se insere no contexto do Cadastro, por isso se faz necessário introduzir o assunto antes de entrar no conceito de mapeamento cadastral propriamente dito.

De acordo com Wakker, Molen e Lemmen (2003), o primeiro Cadastro com conceito semelhante ao dos dias atuais foi o da Holanda, finalizado em 1832. Em 1808, Napoleão Bonaparte necessitando de recursos para financiar suas atividades, decidiu estabelecer um cadastro fiscal na França baseado em um acurado inventário do uso e da propriedade da terra com um levantamento topográfico preciso de cada parcela. Em 1795 a Holanda foi ocupada e posteriormente anexada pela França, devendo obedecer a sua legislação. Em 1811, a Holanda passou a fazer parte do sistema cadastral francês, iniciando o levantamento topográfico e da propriedade da terra no ano seguinte. Com a independência da Holanda, após a queda de Napoleão em 1815, o Rei William I deu continuidade aos trabalhos e em 1832 o cadastro foi completado para todo o país.

O Cadastro tem diferentes definições e funções dependendo do país. Contudo, a Fédération Internationale dês Géomètres (FIG) - instituição que provê fórum para discussão internacional e desenvolvimento na promoção da prática profissional e de padrões nas áreas de topografia, geomática, geodésia e geoinformação - define-o como (grifo nosso):

... um inventário público metodicamente organizado de dados referentes a propriedades dentro de um determinado país ou distrito baseado no mapeamento dos seus limites. Estas propriedades são sistematicamente identificadas através de uma designação individual. Os contornos da propriedade e o identificador da parcela normalmente são representados em mapas de grandes escalas, os quais juntamente com os registros, podem mostrar para cada uma das propriedades a natureza, tamanho, valor e direitos legais associados à parcela. Ele provê a resposta à questão onde e quanto (KAUFMANN e STEUDLER, 1998; p. $13)$.

A definição da FIG introduz conceitos importantes que diferenciam o mapeamento topográfico do mapeamento cadastral, como é o caso dos conceitos de parcela e identificador único, os quais serão tratados nos 
próximos parágrafos. As palavras em destaque evidenciam o caráter temático do mapeamento cadastral quando dizem que são dados referentes a propriedades e ao mapeamento dos limites das mesmas.

Além disso, essa definição comporta o conceito universal de Cadastro que prevê a união das bases dos Registros de Imóveis, as quais contêm as características legais da propriedade, aos sistemas de informações cadastrais dos municípios, os quais contêm as características físicas das propriedades.

Neste momento é importante abrir um parênteses, antes de prosseguirmos com o entendimento do Cadastro, pois o próprio uso do termo Cadastro também tem suas peculiaridades em nosso país.

No Brasil, os sistemas de informações cadastrais dos municípios são chamados de "Cadastro". Esses sistemas de informações cadastrais e o Registro de Imóveis são realizados separadamente, embora sejam complementares.

Ciente dos problemas advindos dessa situação, a portaria $\mathrm{n}^{\circ} 511$ de 2009 do Ministério das Cidades (BRASIL, 2009), já utiliza o conceito universal de Cadastro. A portaria prevê a coordenação entre as informações do Registro de Imóveis e as informações dos sistemas de informações cadastrais dos municípios, doravante denominados de Cadastro Territorial Multifinalitário (CTM), respeitando-se as respectivas competências. De acordo com o artigo $4^{\circ}$ da portaria, as informações do CTM, quando correlacionados às informações do Registro de Imóveis (RI) constituem o Sistema de Cadastro e Registro Territorial (SICART).

Nesse artigo nos ativemos à legislação urbana, mas o conceito de Cadastro engloba tanto as parcelas urbanas quanto as rurais. No Brasil, o cadastro rural é realizado através do Sistema de Gestão Fundiária (SIGEF) do Instituto Nacional de Colonização e Reforma Agrária (INCRA), responsável pela realização do ordenamento fundiário nacional. Entretanto, o mapeamento cadastral rural tem normas para o levantamento topográfico, mas não para a representação 
cartográfica. Futuramente, o Sistema Nacional de Gestão de Informações Territoriais (SINTER) pretende integrar os dados cadastrais urbanos e rurais. A par dessas informações, podemos continuar com o entendimento do conceito de Cadastro.

Quanto ao significado de parcela, de acordo com o Land Administration Domain Model (LADM) (ISO 19152, 2012, pg. 2) - um padrão internacional de gestão territorial, iniciado pela $F I G$ e pela $O N U$ UN-HABITAT, o programa das Nações Unidas para os Assentamentos Humanos - a parcela é definida como:

\begin{abstract}
A unidade administrativa básica (...) contra a qual (...) direitos únicos e homogêneos (...), responsabilidades ou restrições, estão associados à entidade como um todo, quando incluída em um sistema de administração territorial (ISO 19152, 2012, pg. 2).
\end{abstract}

Para melhor compreensão, uma unidade administrativa básica deve ter um identificador único quando registrado ou gravado no sistema. Único significa que um direito, restrição ou responsabilidade é exercida por uma ou mais partes (proprietários ou usuários) para toda a parcela. Homogêneo significa que um direito, restrição ou responsabilidade (propriedade, uso, posse, ocupação, arrendamento ou servidão) afeta toda a parcela (ISO 19152, 2012).

O $L A D M$ enquanto padrão internacional que apresenta uma síntese dos sistemas de administração territorial existentes mostra, através de seus pacotes de informação, as relações entre os atores envolvidos no Cadastro: a parte ou interessado representa a pessoa física ou jurídica, ocupante e/ou proprietário(s) da propriedade; o administrativo diz respeito aos direitos, restrições e responsabilidades sobre a unidade imobiliária (a classe unidade administrativa básica referente à parcela faz parte deste pacote); e por fim, um pacote com dois elementos, a unidade espacial que descreve as classes de informações espaciais da unidade territorial que permitem o relacionamento com o indivíduo e, o levantamento topográfico e representação, que é um sub-pacote da unidade espacial, o qual se refere aos dados do levantamento 
topográfico e as representações cadastrais geométricas e topológicas (ISO 19152, 2012). De acordo com as informações apresentadas ao longo dessa seção, a definição de Cadastro envolve três atores: os sistemas de informações cadastrais dos municípios, o registro de imóveis e, o mapeamento topográfico em grandes escalas. Os sistemas de informações cadastrais dos municípios têm como finalidade a arrecadação municipal através de impostos e o ordenamento territorial, bem como fornecer subsídios para a tomada de decisões no planejamento urbano, por isto deve ser o mais atualizado possível (BRASIL, 1980). A finalidade do registro de imóveis é declarar publicamente a titularidade do imóvel e manter atualizada a sua situação jurídica através de sua matrícula (AUGUSTO, 2013). O mapeamento topográfico em grandes escalas no contexto do Cadastro, tem como finalidade servir de base e referência espacial à representação gráfica detalhada de cada parcela e, sendo assim, fornece informações importantes à caracterização da parcela. A esta representação é dado o nome de carta cadastral ou mapa cadastral (BRASIL, 2010b).

Embora estes três atores tenham finalidades diferentes dentro do Cadastro, ocorre um constante intercâmbio de informações entre eles. O mapeamento topográfico em grandes escalas fornece feições de referência que permitem situar a parcela no espaço e, para auxiliar o registro de imóveis na atualização das responsabilidades, restrições e direitos relacionados às parcelas. Mas o contrário também ocorre, determinadas informações geradas pelo sistema de informações cadastrais e pelo registro de imóveis, quando materializadas no terreno passam a ser representadas no mapeamento topográfico em grandes escalas.

A portaria $n^{\circ} 511$ de 2009 do Ministério das Cidades, (BRASIL, 2009) estabelece as diretrizes para a criação, instituição e atualização do Cadastro, denominado Cadastro Territorial Multifinalitário (CTM), nos municípios brasileiros. Esta diz que, a "cartografia cadastral" deve obedecer aos padrões estabelecidos para a Infraestrutura Nacional de Dados Espaciais (INDE) e 
às normas relativas à Cartografia Nacional, de acordo com o artigo $4^{\circ}$ do Decreto 6.666/2008 (BRASIL, 2008).

Entre as normas técnicas existentes, a NBR 14.166 (ABNT, 1998) estabelece as condições para a implantaçãoe manutenção da Rede de Referência Cadastral Municipal (RRCM) com o objetivo de apoiar a elaboração e a atualização de plantas cadastrais municipais. A Rede de Referência Cadastral Municipal (RRCM) é a rede de apoio em nível municipal para todos os serviços destinados a projetos, cadastros ou implantação e gerenciamento de obras. A RRCM é constituída por pontos de coordenadas horizontais e verticais, materializados no terreno, referenciados a uma única origem, o Sistema Geodésico Brasileiro (SGB), e a um mesmo sistema de representação cartográfica, o que permite a amarração e consequente incorporação de todos os trabalhos de topografia e cartografia na construção e manutenção da Planta Cadastral Municipal. Estas informações demonstram que embora o mapeamento cadastral seja diverso do mapeamento topográfico em grandes escalas, compartilha do mesmo sistema de referência.

Entendido o contexto no qual se insere, é possível agora solidificar o conceito de mapeamento cadastral. A seguir, será analisada uma série de definições internacionais que vem a demonstrar como o mapeamento cadastral tem sido entendido no mundo ao longo do tempo. Cada uma delas traz elementos que juntos dão suporte para uma definição completa.

A American Society for Photogrammetry and Remote Sensing (ISPRS, 1942, pg. 266) define o mapa cadastral como (tradução livre):

Um mapa mostrando os limites das subdivisões de terra, geralmente com seus rumos e comprimentos e as áreas de glebas individuais para fins de descrição e registro de propriedade. Um mapa cadastral também pode mostrar áreas cultivadas, drenagem e outras características relacionadas ao valor e uso da terra. 
O ANZLIC Intergovernmental Committee on Surveying and Mapping’s (ICSM) da Austrália e da Nova Zelândia (ICSM, 2017), diz que (grifo nosso):

Um mapa cadastral é uma ferramenta de administração geral do território (...). Ele é normalmente criado sob demanda e deste modo, não necessariamente atualizado. Estes mapas são utilizados por uma ampla gama de pessoas (público em geral e profissionais) para diversos fins, incluindo a compra e venda de imóveis, avaliação, ordenamento do território, planejamento urbano, etc.

Nesta definição destacamos a palavra ferramenta, que denota que o mapeamento cadastral é uma aplicação no sentido da informática, pois temse como premissa que os sistemas de informações cadastrais são modelados através de Sistemas de Informação Geográfica (SIGs). Além disso, por ser "criado sob demanda" é desenvolvido para satisfazer a determinados usos.

De acordo com o Registers Of Scotland (2017a), o departamento de governo responsável pela compilação e manutenção de dezoito Cartórios de Registros Públicos da Escócia, um mapa cadastral é:

Um mapa que define a propriedade da terra. (...) O mapa cadastral consiste de unidades cadastrais e cada uma delas representa uma única parcela de terra. O mapa cadastral não se limita a definir limites de propriedades, mas inclui referências geoespaciais para outros direitos ou obrigações que afetam as parcelas de terra registradas. Na Escócia, (...) o OrdnanceSurveyMap (OS Map) forma o mapa de base.

A definição acima esclarece que um mapa cadastral é um mapa de uso específico para definir a propriedade da terra, mas que tem como base o mapeamento topográfico em grandes escalas, nesse caso o OS Map, já que inclui referências geoespaciais que influenciam a situação jurídica das parcelas.

De acordo com a Organização das Nações Unidas para a Alimentação e a Agricultura (FAO) (FAO, 2017):

(...) o verdadeiro mapa cadastral cobre todas as parcelas de uma área ao invés de pedaços isolados. (...) pode ter uma escala suficientemente 
grande para que as dimensões de cada parcela possam ser obtidas diretamente no mapa. Um mapa cadastral irá mostrar os limites das parcelas, mas poderá também incorporar os recursos associados a elas, incluindo as estruturas físicas sobre a superfície ou abaixo dela como a sua geologia, solo, vegetação e a maneira como a terra é utilizada.

A definição supracitada, na mesma linha de raciocínio da definição anterior, demonstra a importância das feições retratadas no mapeamento topográfico em grandes escalas como base para o mapeamento cadastral, as quais agregam referências espaciais relativas aos direitos, restrições e responsabilidades, além das informações ambientais, dos recursos e das riquezas da região na qual se insere a parcela. Esta consideração é importante, pois o cadastro deve atender às necessidades sociais, ambientais e econômicas da administração pública (BRASIL, 2009).

Para Philips (2004), a carta cadastral representa a propriedade legal das parcelas, nela são colocados os números cadastrais e as delimitações legais definidas no registro de imóveis. Para o referido autor, a carta cadastral é muitas vezes confundida com a carta topográfica, cujo objetivo é representar as feições visíveis em campo.

Carneiro (2003) explicita o conceito de mapeamento cadastral quando diz que a concepção de um Cadastro começa pela definição de uma rede de referência espacial e um sistema de mapeamento básico, os quais permitem relacionar diversas outras informações à parcela. Sendo assim, incluem o mapeamento dos limites de lotes, glebas, vias, praças, lagos e rios, entre outros, sobre os quais são acrescentadas informações temáticas como os cadastros fiscais, logradouros, edificações, infraestrutura, ambientais e socioeconômicas, entre outras, dependendo das necessidades de cada município.

De acordo com as definições analisadas, o entendimento de mapeamento cadastral pressupõe então que seu principal objetivo é representar os limites das propriedades. 


\section{Discussão sobre a Mesclagem do Uso dos Termos no Brasil}

Definidos os conceitos de mapeamento topográfico em grandes escalas e de mapeamento cadastral, foram investigadas as possíveis razões para que estes dois diferentes termos sejam utilizados como sinônimos no país. Citase inicialmente, um precedente internacional em relação ao uso do termo mapeamento cadastral de forma equivocada, o qual pode ter ecoado em terras brasileiras. O termo "levantamento cadastral" (cadastral survey) foi utilizado pelo Ordnance Survey (OS) para designar os levantamentos para produzir mapas em escala 1:2.500 nos anos 1860, durante o período em que Sir. Henry James foi diretor da agência, sendo que o termo nãofoi mais utilizado depois que ele se aposentou em 1875 (Kain e Baigent, 1992).

De acordo com Kain e Baigent (1992), apesar do uso do termo, um levantamento cadastral no sentido de inventariar as propriedades nunca foi previsto e realizado pelo OS. O primeiro mapeamento cadastral de fato, utilizado para cobrança de taxas sobre a propriedade só foi produzido através de legislação introduzida pelo governo da Inglaterra, em 1910.

Em relação ao Brasil, primeiramente, foi examinada a definição que a agência oficial de mapeamento nacional fornece para mapas topográficos. De acordo com o Instituto Brasileiro de Geografia e Estatística (IBGE) (IBGE, 2017a):

Folhas topográficas são representações cartográficas dos elementos geográficos naturais e artificiais da superfície terrestre, e seus respectivos nomes geográficos, disponibilizadas de acordo com o recorte geográfico do Mapeamento Topográfico Sistemático Terrestre do Brasil nas escalas 1:1.000.000, 1:250.000, 1:100.000, 1:50.000 e 1:25.000.

Quanto à utilização, a agência de mapeamento brasileira diz que, estas se constituem nas bases de referência sobre as quais se operacionalizam a espacialização de diferentes informações temáticas e o conhecimento do território para o planejamento de ações do setor público e privado (IBGE, 2017a). 
Esta definição pode levar à interpretação de que o mapeamento topográfico em grandes escalas não faz parte do mapeamento topográfico sistemático terrestre do Brasil. Ela se relaciona diretamente à questão das competências institucionais dada pela redação do decreto $\mathrm{n}^{0} 243$ (BRASIL, 1967) que fixa as diretrizes e bases da cartografia brasileira.

O decreto-lei no 243 (BRASIL, 1967) diz que a cartografia sistemática terrestre tem por fim a representação da área nacional, através de séries de cartas gerais contínuas, homogêneas e articuladas, nas escalas-padrão supracitadas. Para estas escalas a competência para a produção e o estabelecimento das normas técnicas é do IBGE. Para o caso das escalas maiores que 1:25.000 a competência para o estabelecimento das normas técnicas é da Diretoria do Serviço Geográfico (DSG). Contudo, em relação à competência para a produção destes mapas, além da DSG, ela também é delegada aos órgãos federais, estaduais e municipais através de contratação da iniciativa privada (BRASIL, 2010a, p. 64, 71 e 72). No que diz respeito às normas, somente com o estabelecimento da Infraestrutura Nacional de Dados Espaciais (INDE), em 2008, estas começaram a ser lançadas.

Tanto no decreto-lei $\mathrm{n}^{\circ} 243$ (BRASIL, 1967), quanto no decreto $\mathrm{n}^{\circ}$ 89.817 (BRASIL, 1984), que estabelece as instruções reguladoras das normas técnicas da cartografia nacional, não é mencionado o termo "cadastral" para o mapeamento topográfico em grandes escalas. Entretanto, no Plano de Ação da INDE (BRASIL, 2010a, p.72) e nas definições de (IBGE, 2017b) que serão apresentadas a seguir, o termo "cadastral" é utilizado para designar o mapeamento topográfico em grandes escalas.

No seu site, o IBGE (IBGE, 2017b) apresenta uma classificação de cartas e mapas quanto à natureza da representação, na qual a diversidade de nomenclaturas leva a uma confusão ainda maior. Segundo essa publicação os mapas são classificados primeiramente em gerais, temáticos ou especiais (os dois últimos não serão discutidos, pois não fazem parte do escopo deste artigo). De acordo com o IBGE, os mapas gerais têm como objetivo prover uma base cartográfica "com possibilidades de aplicações 
generalizadas, de acordo com a precisão geométrica e tolerâncias permitidas pela escala" e servir de base para outros tipos de mapas. Segundo esse documento, os mapas gerais são subdivididos em cadastrais, topográficos e geográficos. Segundo a publicação, os mapas cadastrais (com escalas até 1:25.000), são utilizados "para representar cidades e regiões metropolitanas, nas quais a densidade de edificações e arruamento é grande", entretanto, não cita como finalidade a representação da propriedade das parcelas. Em relação aos mapas topográficos (escalas de 1:25.000 até 1:250.000), o IBGE diz que estes incluem os acidentes naturais e artificiais e cujos elementos planimétricos e altimétricos são "geometricamente bem representados". Quanto aos mapas geográficos (escalas 1:1.000.000 e menores), a publicação diz que são mapas cujos "detalhes planimétricos e altimétricos são generalizados, os quais oferecem uma precisão de acordo com a escala de publicação". São os mapas do Brasil, regionais e estaduais.

Estas nomenclaturas, bem como as suas definições, com entendimentos diversos daqueles discutidos neste artigo, estão atrelados à estrutura institucional e às competências de cada uma das coordenações da Diretoria de Geociências do IBGE.

A recente ET-EDGV 3.0 - Especificações Técnicas para Estruturação de Dados Geoespaciais Vetoriais (DSG, 2017) já utiliza os termos mapeamento topográfico em grandes escalas (MapTopoGE) e mapeamento topográfico em pequenas escalas (MapTopoPE), de forma análoga à conceituação proposta neste artigo.

$\mathrm{Na}$ modelagem das categorias de informação da ET-EDGV 3.0 existem os dois esquemas MapTopoPE e MapTopoGE, mas a modelagem inclui categorias que são únicas para todas as escalas, prevendo a aplicação da generalização cartográfica. Deste modo, a especificação visa a manter a congruência das informações geoespaciais entre as escalas, ou seja, a imagem das feições é inequívoca e definitivamente legível em todas as escalas-padrão produzidas, observando o preceito de continuidade, 
homogeneidade e articulação das séries de cartas da cartografia sistemática brasileira, previstas no decreto-lei n ${ }^{\circ} 243$ (BRASIL, 1967).

Contudo, a ET-EDGV 3.0 (DSG, 2017, p.7) diz que "o mapeamento topográfico em grandes escalas, no âmbito das prefeituras municipais, é denominado por Cartografia Cadastral", entendimento este, diverso daquele discutido neste artigo.

No que diz respeito ao mapeamento cadastral, a portaria $n^{\circ} 511$ (BRASIL, 2009) traz uma definição que pode trazer interpretações equivocadas: "a carta cadastral é a representação cartográfica do levantamento sistemático territorial do município". Contudo, uma das diretrizes da portaria diz que o mapeamento cadastral deve seguir as normas designadas pela INDE, não determinando se o mapeamento de referência para o cadastro deve seguir tais normas, ou que a INDE deveria também produzir padrões para o cadastro em si. $\mathrm{O}$ artigo $2^{\circ}$ da mesma portaria reforça que o mapeamento cadastral se sobrepõe ao mapeamento topográfico que representa a superfície terrestre do município, demonstrando que cada parcela tem regime jurídico individual:

Art. $2^{\circ}$ A parcela cadastral é a menor unidade do cadastro definida como uma parte contígua da superfície terrestre com regime jurídico único. $\S 1^{\circ}$ É considerada parcela cadastral toda e qualquer porção da superfície no município a ser cadastrada.

$\S 2^{\circ}$ As demais unidades, como, lotes, glebas, vias públicas, praças, lagos, rios e outras, são modeladas por uma ou mais parcelas de que trata o caput deste artigo, identificadas por seus respectivos códigos.

O Manual de Apoio - Diretrizes para a Criação, Instituição e Atualização do Cadastro Territorial Multifinalitário nos Municípios Brasileiros do Ministério das Cidades (BRASIL, 2010b, p. 37) distingue os conceitos de carta topográfica e carta cadastral de acordo com o entendimento discutido neste artigo. O manual diz ainda que (BRASIL, 2010b, p. 35):

O objeto da cartografia cadastral é fundamentalmente representar o levantamento 'sistemático' dos limites das parcelas territoriais, de modo 
que estas apresentem localização geográfica única. Entre os elementos cartográficos essenciais, encontram-se o sistema de coordenadas, o sistema de projeção, as escalas gráfica e numérica, bem como o mapa de localização.

Esta observação do Manual mostra que, embora o objeto do mapeamento cadastral seja a representação da estrutura fundiária do município, este também utiliza o mapeamento topográfico em grandes escalas como base, pois os elementos de representação supracitados não são diferentes daqueles constantes do mapeamento topográfico em grandes escalas (BRASIL, 2010b, p. 39-40). Hasenack, Cabral e Philips (2013, pg. 286), embora busquem discernir os papeis do mapeamento cadastral e o do mapeamento topográfico em grandes escalas, acabam por separar os conceitos mais pela forma de aquisição dos dados do que pela finalidade de cada mapeamento:

As cartas topográficas são resultado de levantamentos topográficos, geodésicos, fotogramétricos e outros métodos que proporcionem precisões compatíveis, sendo realizados em grandes áreas, normalmente em curto espaço de tempo e com grande dificuldade de atualização. O objeto da cartografia cadastral é o levantamento sistemático dos limites das parcelas territoriais, de modo que possuam suas áreas definidas com localização única, bem como seus limites identificados através de valores descritivos, gráficos e numéricos, referenciados ao sistema geodésico oficial, com exatidão e precisão necessária às exigências da Lei.

Para eles, Hasenack, Cabral e Philips (2013, pg. 289), faz-se necessário "a revisão das normas e procedimentos com uma visão que contemple a Carta Cadastral como base geométrica única para as demais cartas", reforçando a mesclagem dos conceitos. Estes autores chegaram à conclusão de que não existe carta cadastral no Brasil: "nas prefeituras após análise e aprovação o que resulta é uma coleção de plantas que não servem para montar um mosaico do território a que pertencem”. Provavelmente, isto se deve ao fato de não haver o mapeamento topográfico em grandes escalas como base para colocar cada peça do mosaico cadastral na posição correta. 
A NBR 13.133/1994 Execução de Levantamento Topográfico (ABNT, 1994) que é utilizada como uma das referências normativas para o mapeamento cadastral (embora esteja, juntamente com a NBR 14166/1998, em atualização), traz definições que colaboram para a ambiguidade na utilização dos termos no país tanto na comunidade técnica, como na comunidade científica.

A referida norma diz, em seu glossário de definições que, os levantamentos topográfico planimétrico cadastral e planialtimétrico cadastral (ABNT, 1994, p. 3), tem como objeto a determinação da posição de detalhes visíveis no nível e acima do solo tais como, "limites de vegetação ou de culturas, cercas internas, edificações, benfeitorias, posteamentos, barrancos, árvores isoladas, valos, valas, drenagem natural e artificial, etc.". Contudo, nessa definição, a determinação da posição dessas feições dá o nome a uma técnica de levantamento, a qual pode ser utilizada para diversas finalidades.

Por fim, além do aspecto conceitual e técnico, outra possível razão que colabora para a ambiguidade na utilização dos termos mapeamento topográfico em grandes escalas e mapeamento cadastral no Brasil é a exígua cultura cadastral e também cartográfica no país. O Manual de Apoio do CTM diz que (BRASIL, 2010b, p. 9):

A ausência de cadastros territoriais e mapeamentos confiáveis é uma das características de grande parte dos (5.570) municípios brasileiros. Essa realidade tornou-se mais evidente com a necessidade de aprovação dos planos diretores participativos e pela perspectiva de implementação dos instrumentos urbanísticos previstos no Estatuto da Cidade.

\section{Resultados}

Após o estudo e a análise das definições de mapeamento topográfico em grandes escalas e de mapeamento cadastral, algumas delas com visões distintas das argumentadas neste artigo, observou-se que, entre as que compartilham da visão conceitual defendida, algumas características são 
prevalentes para cada um dos mapeamentos. Ao sintetizar essas características foi possível gerar uma definição completa, de acordo com o raciocínio para o entendimento atual do conceito de cada tipo de mapeamento.

Tanto para o mapeamento topográfico em grandes escalas quanto para o mapeamento cadastral, foram analisadas oito definições consideradas conceitualmente coerentes com a visão argumentada, sendo sete na seção específica do mapeamento e uma na seção da discussão da mesclagem dos conceitos.

No mapeamento topográfico em grandes escalas as características prevalentes são mostradas com ênfase na Figura 1:

Figura 1- Características prevalentes nas definições de mapeamento topográfico (traduções nossas, quando conceitos em inglês)

KEATES, 1973: nos mapas topográficos são representadas "todas as feições identificáveis da superfície da Terra, tanto naturais como artificiais, para as quais é possível estabelecer uma posição especifica, expressa em relação à superficie topográfica" e, seu propósito fundamental é representar as feições em suas posições, acurada e precisamente, dentro dos limites da escala. (DENT, 1999): "são mapas de uso geral, cuja ênfase está na localização". Eles representam os objetos naturais e os construídos pela humanidade como: hidrografia, vegetação, relevo, estradas, edificações, limites politicos, entre outros. (NATURAL RESOURCES CANADA, 2017): "uma ilustração detalhada e acurada de feições naturais e feitas pelo homem no terreno como estradas, ferrovias, linhas de transmissão de energia, curvas de nível, elevações, rios, lagos e nomes geográficos".

(USGS, 2008): “A característica que distingue um mapa topográfico de outros tipos de mapas é o uso de curvas de nível para representar a forma e elevação da superfície da Terra. Os mapas topográficos representam as elevações e depressões tridimensionais do terreno sobre uma superfície bidimensional".

(LAND INFORMATION NEW ZEALAND, 2017): "representações gráficas dos elementos que aparecem na superfície da Terra, as quais incluem feições culturais, de hidrografia, relevo e vegetação".

(GEOSCIENCE AUSTRALIA, 2017): são utilizados para fins recreativos como viagens, caminhadas e orientação, mas também são utilizados pelo governo e pela indústria para auxiliar no planejamento urbano, na mineração, na gestão de emergências e para o estabelecimento de limites legais e de propriedade da terra.

(ORDNANCE SURVEY, 2017): "também inclui objetos intangíveis como limites municipais e as linhas de águas médias, altas ou baixas". Base para as mais diversas e elaboradas aplicações.

(IBGE, 2017): "representações cartográficas dos elementos geográficos naturais e artificiais da superfície terrestre, e seus respectivos nomes geográficos, disponibilizadas de acordo com o recorte geográfico do mapeamento (...) nas escalas padrão".

Fonte: Elaborada pelas autoras.

Com base nestas análises, sugere-se que quando se utilize o termo mapeamento topográfico em grandes escalas tenha-se em mente a seguinte definição:

O mapeamento topográfico em grandes escalas é composto de mapas de uso geral que devem servir a quaisquer usos e usuários, sendo a base cartográfica de referência para diversas aplicações, incluindo outros tipos de mapeamento. O mapeamento topográfico em grandes escalas mostra a localização acurada e precisa de feições naturais e artificiais sobre a 
superfície da Terra e inclui objetos intangíveis como limites territoriais, linhas de águas, curvas de nível e nomes geográficos em escalas padronizadas, maiores do que 1:25.000.

Para o mapeamento cadastral as características prevalentes são mostradas na Figura 2:

Figura 2- Características prevalentes nas definições de mapeamento cadastral (traduções nossas, quando conceitos em inglês)

(AMERICAN SOCIETY FOR PHOTOGRAMMETRY AND REMOTE SENSING, 1942):"'mapa mostrando os limites das subdivisões de terra, geralmente com seus rumos e comprimentos e as áreas de glebas individuais para fins de descrição e registro de propriedade. (...) também pode mostrar áreas cultivadas, drenagem e outras características relacionadas ao valor e uso da terra." (ICSM, 2017): “ “.. é uma ferramenta de administração geral do território (...) são utilizados por uma ampla gama de pessoas (...) para diversos fins, incluindo a compra e venda de imóveis, avaliação, ordenamento do território, planejamento urbano, etc." (REGISTERS OF SCOTLAND, 2017): "um mapa que define a propriedade da terra. (...) mostra todos os dados geoespaciais relacionados às parcelas registradas. (...) consiste de unidades cadastrais e cada uma delas representa uma única parcela de terra. $\mathrm{O}$ mapa cadastral não se limita a definir limites de propriedades, mas inclui referências geoespaciais para outros direitos ou obrigações que afetam as parcelas de terra registradas. (...)"

(FAO, 2017): “(...) cobre todas as parcelas de uma área ao invés de pedaços isolados. Ele pode atuar como um índice para o levantamento de outras parcelas que mostram informações mais detalhadas ou pode ter uma escala suficientemente grande para que as dimensões de cada parcela possam ser obtidas diretamente no mapa. Um mapa cadastral irá mostrar os limites das parcelas, mas poderá também incorporar os recursos associados a elas, incluindo as estruturas físicas sobre a superfície ou abaixo dela como a sua geologia, solo, vegetação e a maneira como a terra é utilizada".

(PHILIPS, 2004): a carta cadastral representa a propriedade legal das parcelas, nela são colocados os números cadastrais e as delimitações legais definidas no registro de imóveis.

(NORMA, 2018): A carta cadastral é obtida através de técnicas de levantamento georreferenciado direto nos padrões do manual (...) são representados todos os limites legais, incluindo os não materializados no terreno e os topônimos de arruamento, os quais provêm do mapeamento topográfico. (...) as parcelas recebem um código unívoco.

(CARNEIRO, 2003) : (...) a concepção de um cadastro começa pela definição de uma rede de referência espacial e um sistema de mapeamento básico, os quais permitem relacionar diversas outras informações à parcela. Sendo assim, incluem o mapeamento dos limites de lotes, glebas, vias, praças, lagos e rios, entre outros, sobre os quais são acrescentadas informações temáticas como os cadastros fiscais, logradouros, edificações, infraestrutura, ambientais e socioeconômicas, entre outras, dependendo das necessidades de cada município.

(BRASIL, 2010b, p. 35): “O objeto da cartografia cadastral é fundamentalmente representar o levantamento 'sistemático' dos limites das parcelas territoriais, de modo que estas apresentem localização geográfica única. Entre os elementos cartográficos essenciais, encontram-se o sistema de coordenadas, o sistema de projeção, as escalas gráfica e numérica, bem como o mapa de localização." Fonte: Elaborada pelas autoras.

Deste modo, sugere-se que quando se utilize o termo mapeamento cadastral tenha-se em mente que:

O objeto do mapeamento cadastral é a representação dos limites legais das propriedades. Sua função é representar e identificar a localização dos limites de cada parcela sobre a superfície da Terra com código unívoco para sistemas cadastrais e registro de propriedade. $\mathrm{O}$ mapeamento cadastral é utilizado como ferramenta de administração e ordenamento do território, no planejamento urbano e para usos específicos como avaliação, compra e venda de imóveis. Na Figura 3, foram criadas nuvens de palavras com os conceitos selecionados nas figuras 1e 2de forma a permitir uma visualização das palavras mais frequentemente utilizadas. "Nuvens de 
palavras" são imagens compostas por palavras de determinado texto com cores, direções e tamanhos diferentes. Essas nuvens representam a frequência com a qual as palavras aparecem nesse texto. As palavras são distribuídas dentro da nuvem conforme essa frequência, de modo que, quanto maior a frequência, maior e mais destacada será a palavra, nesse caso, promovendo uma melhor visualização dos conceitos. As nuvens foram geradas através do site (WORDCLOUDS, 2019).

Observa-se na primeira nuvem que as feições da superfície da Terra têm destaque com ênfase também em outros elementos dos mapas topográficos como limites territoriais ou administrativos, hidrografia, edificações, relevo e vegetação. Na segunda nuvem se pode observar que as palavras: parcelas, limites das parcelas, propriedade e registro são especialmente importantes no contexto do mapeamento cadastral.

Figura 3 - Palavras prevalentes nas definições de mapeamento topográfico e cadastral
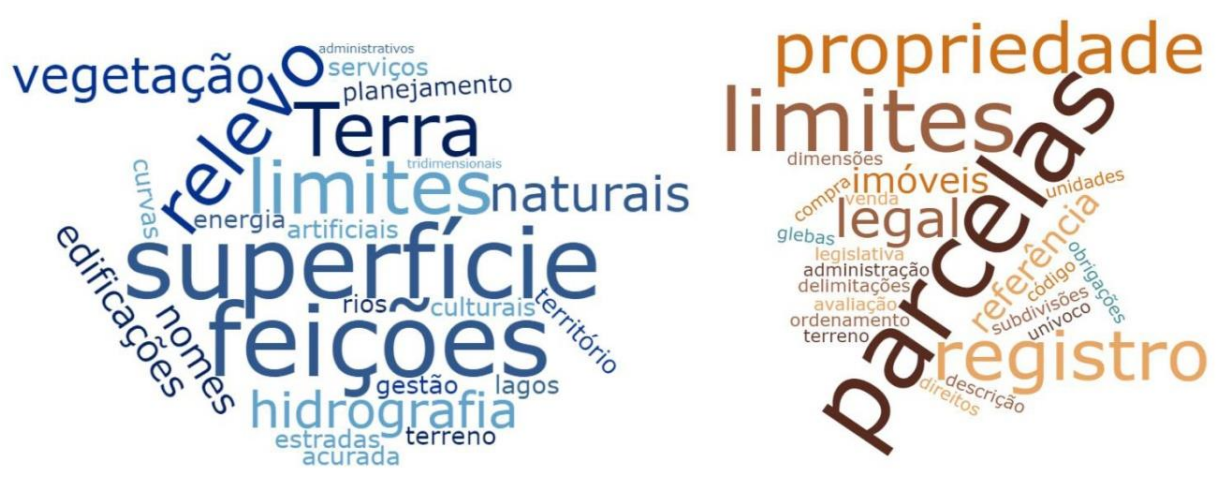

Fonte: Elaborada pelas autoras.

\section{Conclusões}

Ao longo deste artigo foram analisadas as definições de mapeamento topográfico em grandes escalas e de mapeamento cadastral, bem como, as possíveis razões para que estes dois diferentes termos sejam utilizados como sinônimos no Brasil. 
Entendeu-se que os dados geoespaciais para os mapeamentos em questão precisam ser gerados segundo padrões que garantam o seu compartilhamento, interoperabilidade e disseminação, sendo estes aspectos fundamentais para uma cartografia, seja ela sistemática ou cadastral, efetiva no país e de acordo com as diretrizes da Infraestrutura Nacional de Dados Espaciais (INDE) e do Sistema Nacional de Gestão de Informações Territoriais (SINTER). A semântica, ao definir o significado dos termos utilizados é um fator primordial à interoperabilidade.

Deduziu-se que o desacordo entre as definições dos mapeamentos analisados pode ser um fator que tem dificultado a resolução de problemas relacionados à sua padronização e levado a resultados divergentes pelas iniciativas que usam o mesmo termo, sob diferentes lógicas conceituais.

Com base na análise dos termos investigados foram sugeridas duas definições que contemplam as características mais importantes de cada um dos mapeamentos, tornando evidentes as suas diferenças, a importância de cada um e quais os seus papeis dentro da cartografia em grandes escalas no Brasil.

Neste cenário, espera-se que com a desambiguação dos termos mapeamento topográfico em grandes escalas e mapeamento cadastral, seja possível contribuir para a estruturação e consolidação de um mapeamento topográfico em grandes escalas padronizado e atualizado no Brasil, de acordo com as normas e padrões existentes, sob as diretrizes da INDE, bem como de um mapeamento cadastral, também padronizado e atualizado, que atenda melhor as necessidades dos municípios brasileiros, e com a participação dos diversos atores do setor público federal, estadual, municipal; da iniciativa privada; da academia e da sociedade em geral. 


\section{Contribuição dos Autores}

Adriana Alexandria Machado escreveu o artigo, fez a revisão de literatura e a análise dos conceitos. Silvana Philippi Camboim fez a orientação conceitual e a concepção das nuvens de palavras.

\section{Referências}

ABNT. Associação Brasileira de Normas Técnicas. NBR 13133: Execução de Levantamento Topográfico. Rio de Janeiro, 1994.

ABNT. Associação Brasileira de Normas Técnicas. NBR 14166: Rede de referência cadastral municipal - Procedimento. Rio de Janeiro, 1998.

ISPRS. American Society for Photogrammetry and Remote Sensing. Definitions of Terms Used in Photogrammetric Surveying and Mapping. American Society For Photogrammetry Photogrammetric Engineering \& Remote Sensing, vol. 8, n. 4, december 1942. pp. 247-283. Site $<$ https://www.asprs. org>, acessado em 14 de Abril de 2018.

AUGUSTO, E. A. A. Registro de Imóveis retificação de Registro e Georreferenciamento: Fundamento e Prática. Editora Saraiva, 2013. $472 \mathrm{p}$.

BRASIL. Decreto $n^{\circ}$ 243, de 28 de Fevereiro de 1967. Fixa as Diretrizes e Bases da Cartografia Brasileira. Brasília, Diário Oficial da União, 28 de Fevereiro de 1967. Site <http://www.inde.gov.br/legislacao .html>, acessado em 11 de agosto de 2018.

BRASIL. Manual do Cadastro Imobiliário. Projeto CIATA/SERPRO do Ministério da Fazenda, 1980. Apostila de treinamento.

BRASIL. Decreto $n^{0} 89.817$, de 20 de junho de 1984. Estabelece as Instruções Reguladoras das Normas Técnicas da Cartografia Nacional. Brasília, Diário Oficial da União, 20 de junho de 1984. Site <http://www.planalto.gov.br/ccivil_03/decreto/19801989/D89817.htm>, acessado em 11 de agosto de 2018.

BRASIL. Decreto $\mathbf{n}^{\mathbf{0}} \mathbf{6 . 6 6 6}$, de 27 de novembro de 2008. Institui a Infraestrutura Nacional de Dados Espaciais - INDE, e dá outras providências. Brasília, Diário Oficial da União, 27 de novembro de 2008. 
Site <http://www.inde.gov.br/images/inde/20@Decreto6666_27112008.pdf>, acessado em 04 de julho de 2018.

BRASIL. Portaria $n^{\circ}$ 511, de 7 de dezembro de 2009. Diretrizes para a criação, instituição e atualização do Cadastro Territorial Multifinalitário (CTM) nos municípios brasileiros. Brasília, Diário Oficial da União, 7 de dezembro de 2009. Site $<$ https://www.cidades.gov.br/images/stories/ArquivosSNPU/Biblioteca/Planela mentoUrbano/Portaria_511_PROEXT.pdf>, acessado em 8 de julho de 2018.

BRASIL. Ministério do Planejamento, Orçamento e Gestão - Comissão Nacional de Cartografia (CONCAR). Plano de Ação para Implantação da Infraestrutura Nacional de Dados Espaciais - INDE, 2010a. Site $<$ http://www.inde.gov.br>, acessado em 28 de julho de 2017.

BRASIL. Ministério das Cidades. Manual de Apoio - CTM: Diretrizes para a criação, instituição e atualização do cadastro territorial multifinalitário nos municípios brasileiros. CUNHA, E. M. P. \& ERBA, D. A. (Org.). Brasília, 2010b. 170p. ISBN: 978-85-7958-018-5.

BRASIL. Decreto $n^{\circ} 8.764$ de 19 de Maio de 2016. Institui o Sistema Nacional de Gestão de Informações Territoriais e regulamenta o disposto no art. 41 da lei 11.977 de 7 de Julho de 2009. Brasília, Diário Oficial da União, 19 de Maio de 2016. Site <http://www.planalto.gov.br/ccivil_03/_ato20152018/2016/decreto/D8764.htm, acessado em 31 de março de 2018.

CARNEIRO A. F. T. Cadastro Imobiliário e Registro de Imóveis. Instituto de Registro Imobiliário do Brasil, Editor Sergio Antonio Fabris, Porto Alegre, 2003. 259 p.

CAMBOIM, S. P. \& SLUTER, C. R. The National Topographic Mapping as an Indispensable Database for a Brazilian National Spatial Data Infrastructure (NSDI). Proceedings of 24th International Cartographic Conference. Santiago, Chile, 2009. pp. 15-21.

CAMBOIM, S. P.; BRAVO, J.V.M. \& SLUTER, C.R. An investigation into the Completeness of, and the Updates to, OpenStreetMap Data in a Heterogeneous Area in Brazil. ISPRS International Journal of GeoInformation, 4 (3), 2015, pp. 1366-1388. 
CASTANEDA FILHO, R. M. Uma Ontologia de Referência para o Domínio das Divisões e Limites Geográficos Territoriais do Brasil. Tese de doutoramento. Universidade Federal do Rio de Janeiro, Programa de PósGraduação em Geografia, Rio de Janeiro, 2017. 633p.

CARISSIMI, E.; ETGES, V. E.; COLLISCHONN, E. Diagnóstico da Cartografia no Brasil e no Rio Grande do Sul frente ao Paradigma Geotecnológico e o Desenvolvimento Regional. Comissão Econômica para a América Latina e o Caribe (CEPAL) - 60 anos de Desenvolvimento na América Latina, Santa Cruz do Sul, RS, Brasil, 17 a 19 de agosto de 2011. pp. $1-24$.

CONCAR. Comissão Nacional de Cartografia. Diretoria de Geociências (DGC), Coordenação de Cartografia (CCAR), 2006. Mapeamento Cadastral Necessidade de Normatização. Site <http://www.concar.gov.br/detalhe Documentos.aspx?cod=324>, acessado em 01 de junho de 2018.

DENT, B. D. Cartography: Thematic Map Design. 5th ed. McGraw-Hill, Boston, 1999.417 p.

DSG. Diretoria do Serviço Geográfico - Exército Brasileiro. ET-EDGV Defesa F Ter - Especificação Técnica para a Estruturação dos Dados Geoespaciais Vetoriais da Defesa da Força Terrestre, $2^{\text {a }}$ Edição, 2016a. Site <http://www.geoportal.eb.mil.br/index.php/inde2?id=142>, acessado em 2 de agosto de 2018.

DSG. Diretoria do Serviço Geográfico - Exército Brasileiro. ET-ADGV Especificação Técnica para Aquisição de Dados Geoespaciais Vetoriais de Defesa da Força Terrestre, $1^{\text {a }}$ Parte, $2^{\text {a }}$ Edição, 2016b. Site <http://www.geoportal.eb.mil.br/index.php/inde2?id=142>, acessado em 15 de abril de 2018.

DSG. Diretoria do Serviço Geográfico - Exército Brasileiro. ET-EDGV 3.0 Especificações Técnicas para Estruturação de Dados Geoespaciais Vetoriais. Dezembro $2017 . \quad$ Site <http://www.geoportal.eb.mil.br/portal/inde2?id =139>, acessado em 01 de julho de 2018. 
FAO. Organização das Nações Unidas para a Alimentação e a Agricultura. Cadastral Maps. Site http://www.fao.org/docrep/006/v4860e/v4860e03.htm, acessado em 10 de agosto de 2018.

GEOSCIENCE AUSTRALIA. What is a Topographic Map? Site $<$ http://www.ga.gov.au/scientific-topics/nationallocationinformation /topographic-maps-data/basics/what-is-a-topographic-map>, acessado em 4 de dezembro de 2017.

HASENACK, M. A Cartografia Cadastral no Brasil. Tese de doutoramento. Universidade Federal de Santa Catarina, Programa de Pós-Graduação em Engenharia Civil, Centro Tecnológico, Florianópolis, 2013. 201p. Site $<$ https://repositorio.ufsc.br/handle/123456789/107431>, acessado em 10 de Agosto de 2017.

HASENACK, M.; CABRAL, C. R.; PHILIPS, J. W. A Percepção da Carta Cadastral no Brasil. Revista Brasileira de Cartografia 65(2), 2013, pp. 283291.

IBGE. Instituto Brasileiro de Geografia e Estatística. Folhas Topográficas. Site $<$ https://www.ibge.gov.br/geocienciasnovoportal/cartas-e-mapas/folhastopogra ficas.html>, acessado em 5 de dezembro de 2017a.

IBGE. Instituto Brasileiro de Geografia e Estatística. Noções Básicas de Cartografia. Site <https://ww2.ibge.gov.br/home/geociencias/cartografia /manual_nocoes/representacao.html>, acessado em 10 de dezembro de 2017b.

IBGE. Instituto Brasileiro de Geografia e Estatística. Guia das atividades de Geociências do IBGE para Jornalistas. Ed. IBGE, Diretoria de Geociências. Rio de Janeiro, 2015, 51p. Site $<$ https://biblioteca.ibge.gov.br/bibliotecacatalogo.html?id=293539\&view=detal hes>, acessado em 16 de dezembro de 2017 c.

IBGE. Instituto Brasileiro de Geografia e Estatística. IBGE Cidades. 2018. Site $<$ https://cidades.ibge.gov.br>, acessado em 21 de janeiro de 2018.

ICSM. Intergovernmental Committee on Surveying and Mapping's. How is a Cadastral Map different to a Cadastral Plan? Site<http http://www.icsm.gov.au/education/fundamentals-mapping/typesmaps/cadastral-maps-and-plans>, acessado em 13 de junho de 2019. 
IRIB. Instituto de Registro Imobiliário do Brasil. Registro de imóveis: SINTER Será o Único Instrumento de Controle das Informações Repassadas à $\begin{array}{lll}\text { Receita } & \text { Federal, } & \text { 21/06/2016. Site }\end{array}$ $<$ http://www.irib.org.br/noticias/detalhes/registro-de-imoveis-sinter-sera-ounico-instrumento-de-controle-das-informacoes-repassadas-a-receitafederal>, acessado em 20 de janeiro de 2018.

ISO 19152:2012 Geographic information - Land Administration Domain Model (LADM). International Organization for Standardization, 2012.

KAIN, R.J.P. \& BAIGENT, E. The Cadastral Map in the Service of the State - A History of Property Mapping. The University of Chicago Press Ltd., London, $1992.356 \mathrm{p}$.

KAUFMANN, J. \& STEUDLER, D. with the Working Group 1 of FIG Commission 7. Cadastre 2014 - A Vision for a Future Cadastral System, July 1998. Site <www.fig.net/pub/figpub/pub61/Figpub61.pdf>, acessado em 09 de dezembro de 2017.

KEATES, J. S. Cartographic Design and Production. New York, EUA, 1973. $240 \mathrm{p}$

KONVITZ, J. W. The nation-state, Paris and cartography in eighteenth and nineteenth-century France. Journal of Historical Geography, 16(1), 1990. pp. 3-16.

LAND INFORMATION NEW ZEALAND. Map Reading Guide - How to use a Topographic map 1:50.000. Site <https://www.linz.govt.nz /land/maps/topographic-maps>, acessado em 4 de dezembro de 2017.

MACHADO, A. A. \& CAMBOIM, S. P. Diagnóstico da Perspectiva do Usuário na Criação de Infraestruturas de Dados Espaciais Subnacionais: Estudo de Caso para a Região Metropolitana de Curitiba. Revista Brasileira de Cartografia 68(8), 2016. pp. 1633-1651.

NATURAL RESOURCES CANADA. Topographic maps: the basics. Site $<$ https://www.nrcan.gc.ca/sites/www.nrcan.gc.ca/files/earthsciences/pdf/ topo101/pdf/mapping_basics_e.pdf>, acessado em 4 de dezembro de 2017.

OLTEANU-RAIMOND, A.-M.; HART, G.; FOODY, G.; TOUYA, G.; KELLENBERGER, T.; DEMETRIOU, D. The scale of VGI in map production: 
A perspective of European National Mapping Agencies. Transactions in GIS 21(1), 2017. pp. 74-90.

\section{ORDNANCE SURVEY. OS MasterMap Topography Layer Product Guide.} v2, 08/2017. Site <https://www.ordnancesurvey.co.uk/docs/productguides/osmastermap-topography-layer-product-guide.pdf $>$, acessado em 4 de dezembro de 2017.

PEREIRA, K. D.; AUGUSTO, M. J. C.; SANTOS, C. J. B.; FREITAS, A. L. Atualização da Legislação Cartográfica: Necessidade Nacional. Anais do XXI Congresso Brasileiro de Cartografia, Belo Horizonte, 2003. Site <www.ibge.gov.br/.../2003/XXI_Congresso_Brasileiro_de_Cartografia/CBC_20 03_WORK_GT6_D.pdf>, acessado em 17 de dezembro de 2017.

PERRET, J.; GRIBAUDI, M.; BARTHELEMY, M. Roads and cities of 18th century France. Scientific Data, 2, 150048, 2015. pp. 1-7.

PHILIPS, J. W. Breve histórico do cadastro de imóveis no mundo. Boletim do IRIB em revista $n^{\circ}$ 317, São Paulo, 2004. Site <http://iribnet.com.br /revista/reserva/revista317/317.pdf>, acessado em 16 de dezembro de 2017.

$\begin{array}{lll}\text { REGISTERS } & \text { OF SCOTLAND. Site }\end{array}$ $<$ https://www.ros.gov.uk/services/registration/landregister/faqs/cadastralmapping-overview $>$, acessado em 8 de dezembro de 2017 a.

$\begin{array}{lll}\text { REGISTERS } & \text { OF } & \text { SCOTLAND. }\end{array}$ <https://www.ros.gov.uk/services/registration/land-register/faqs/cadastralmapping-deedplanrequirements $>$, acessado em 8 de dezembro de $2017 \mathrm{~b}$.

USGS. United States Geological Survey. Topographic mapping.U.S. Geological Survey Unnumbered Series, GIP, 2008. Site <https://pubs.usgs.gov/gip/topomapping/>, acessado em 19 de Março de 2018.

WAKKER, W. J.; MOLEN, P. V. D.; LEMMEN, C. Land Registration and Cadastre in the Netherlands, and the Role of Cadastral Boundaries: The Application of GPS technology in the Survey of Cadastral Boundaries. Journal of Geospatial Engineering 5(1), 2003. p. 3-10.

WORDCLOUDS. Site <https://www.wordclouds.com/>, acessado em 9 de abril de 2019. 